\title{
Meios auxiliares e caminhos alternativos: o aluno com autismo e a prática pedagógica
}

\author{
Emilene Coco dos Santos* \\ Ivone Martins de Oliveira**
}

\begin{abstract}
Resumo
Este trabalho analisou as possibilidades do uso de meios auxiliares e caminhos alternativos na intervenção pedagógica realizada em uma turma do primeiro ano do ensino fundamental que tinha, entre seus alunos, um menino com autismo. Utilizou, como suporte teórico, a perspectiva histórico-cultural. Constatou que as ações diferenciadas da prática pedagógica se orientaram em duas direções: aspectos organizativos da escola, que procuravam garantir os apoios necessários ao professor regente e ao aluno; ações voltadas especificamente para os processos de ensino e de aprendizagem. Concluiu que investir em ações diversificadas, em colaboração intensiva com a criança e significativas para ela, é um caminho importante para tracionar seu desenvolvimento cultural.
\end{abstract}

Palavras-chave: Educação Especial; Ensino fundamental; Aluno; Autismo.

\section{Auxiliary resources and alternative ways: pupil with autism and the pedagogical practice}

\begin{abstract}
This work analyzed the possibilities of auxiliary resources and alternative ways regarding the pedagogical intervention carried out in a first grade group (Elementary School) having one student with autism among the others in class. As theoretical support, the work used the historic-cultural perspective. It was verified that the differed actions of the pedagogical practice were guided toward two directions: organizational aspects of the school, which intended to guarantee the necessary support given to the ruling Teacher and the pupil; actions specifically aimed at teaching and learning processes. As a conclusion, investing in diversified actions, in intensive collaboration with the children and significant as well, is a crucial path in order to trace their cultural development. Keywords: Special Education; Elementary School; Pupils; Autism.
\end{abstract}

\section{Introdução}

A cada novo ano letivo, milhares de crianças vivem a transição da educação infantil para o ensino fundamental, iniciando o primeiro de nove anos dessa etapa do ensino básico. Esse momento costuma ser vivido pelas crianças e suas famílias com certa expectativa e, às vezes, insegurança, sobretudo para aquelas famílias cujos filhos apresentam alguma deficiência ou transtornos. O estudo realizado por Cruz (2017) a respeito das implicações da implementação do ensino fundamental de nove anos para o desenvolvimento cultural da criança chama a atenção para a ausência de políticas e práticas que visem a preparar a escola para receber a criança de seis que antes se encontrava na educação infantil. Crianças com características diferenciadas ingressam no ensino fundamental, mas têm desconsiderados seus modos típicos de ver o mundo e se relacionar com ele, especialmente no que tange à brincadeira, sua expressão corporal e formas próprias de sociabilidade.

Para a criança com autismo, a transição da educação infantil para o ensino fundamental pode ser um momento mais desafiador ainda do que para as demais crianças, devido tanto às suas peculiaridades como aos questionamentos de alguns profissionais da escola acerca de suas possibilidades de aprendizagem e da implementação de práticas pedagógicas que permitam avançar o seu desenvolvimento.

Há, ainda, muitas dúvidas, desconhecimentos e preconcepções a respeito do autismo. Diferentes perspectivas teóricas buscam uma compreensão dos modos de ser e de estar no mundo de pessoas diagnosticadas com a síndrome. Com diferentes concepções de aprendizagem e de desenvolvimento, algumas dessas perspectivas esboçam propostas educativas ou orientações pedagógicas também com objetivos distintos (VASQUES, 2008).

Para além dos manuais diagnósticos, estudos produzidos na área educacional têm destacado aspectos comuns em crianças com diagnóstico de autismo, ainda que ressaltem o quanto uma criança costuma diferir de outra (CORREIA, 2012; SANTOS, 2012; SANTOS, 2016). As peculiaridades na forma de interação e comunicação, os interesses

*Endereço eletrônico: emilenecoco@ hotmail.com

**Endereço eletrônico: ivone.mo@terra.com.br 
restritos e/ou pouco comuns, bem como a dificuldade em inserir-se na dinâmica dos tempos e espaços da escola são os principais aspectos relatados por muitos estudos da área.

Silva (2011) analisou a prática pedagógica do professor, no processo de inclusão educacional de quatro alunos com autismo no ensino comum, e constatou que a inclusão educacional desses sujeitos ainda é uma experiência nova para os professores observados que tinham pouco conhecimento sobre as especificidades e características diferenciadas desses alunos. A autora aponta a não realização de práticas pedagógicas facilitadoras do aprendizado de todos os estudantes e a necessidade de um investimento em estratégias que facilitem a interação dos alunos com autismo com seus colegas, prioritariamente, na realização de tarefas de grupo. Constatou que as atividades realizadas pelos professores consistiam em ações voltadas para a explicação de conteúdo, aplicação de exercícios, correção dos trabalhos e avaliação. Muitas vezes os professores utilizavam aulas expositivas, nas quais o livro didático e o quadro-negro eram os recursos mais utilizados, o que não contribuía para a aprendizagem dos alunos com autismo, pois faltavam recursos visuais que despertassem sua atenção e interesse.

No processo de escolarização de crianças e jovens com autismo, em alguns casos, como os citados por Ramos (2012), os professores ainda acreditam que o trabalho pedagógico deve tomar como base o diagnóstico médico, pautado em uma lógica classificatória, que enfoca aspectos físicos e motores. A autora constatou que o professor espera um suporte técnico e gerencial para subsidiar sua prática pedagógica com o aluno com autismo ou, ainda, um professor mais experiente, que atue com educação especial.

Algumas pesquisas apontam para o despreparo, desconhecimento, "desespero", dos professores diante da criança com autismo (ANJOS, 2013; CORREIA, 2012). Outras chamam a atenção para não se ter como alvo a síndrome, mas, sim, as potencialidades de cada criança, considerando-a como um sujeito que aprende, capaz de demonstrar o que sabe de modo singular, de participar dos processos interativos, de envolver-se nas descobertas das novidades que a cercam, com o apoio do professor e de seus pares (CRUZ, 2009; CHIOTE, 2011; SALGADO, 2012; EFFGEN, 2017).

Para Cruz (2009), as dificuldades derivadas das insuficiências presentes na criança com autismo são, antes de tudo, significadas pelo grupo social, tanto ao vê-las como capazes quanto incapazes de aprender. Segundo a autora, historicamente, a sociedade tem classificado as pessoas como normais e anormais. Essa dicotomia delimitou posições que terminaram por definir as experiências, as relações e os espaços ocupados pelas pessoas, excluindo da escola quem se desvia do percurso esperado, além de atribuir ao sujeito e à sua deficiência as causas de suas limitações.

Salgado (2012), a partir do olhar da psicanálise, aponta três pontos de impasse no trabalho da inclusão escolar com essas crianças: a estrutura escolar; os fundamentos da pedagogia; e a própria subjetividade das crianças com autismo. A autora destaca que a possibilidade de inclusão desse sujeito está atrelada à capacidade que o professor tem de implicar-se com o ato educativo, de analisar a sua função no processo de escolarização desses alunos.

A pesquisa realizada por Chiote (2011) enfoca os percursos da mediação pedagógica na prática educativa em uma turma de educação infantil em que estava matriculada uma criança com autismo. A autora analisa o movimento de ampliação do olhar de adultos e colegas de turma para essa criança, enfocando os processos interativos e a intervenção dos profissionais de forma a possibilitar avanços em sua inclusão escolar. Afirma que, nesse caso, a prática educativa foi construída num processo de orientar as ações da criança com autismo para o que era esperado dela (e das demais crianças) em diversos tempos e espaços educativos. Nesse percurso, ressaltamos o movimento de realizar para a criança e com ela as atividades propostas no cotidiano do centro de educação infantil, permitindo-lhe a apropriação de conhecimentos e práticas e uma progressiva regulação do próprio comportamento.

Effgen (2017) analisa as intervenções pedagógicas que podem ser planejadas e desenvolvidas em uma perspectiva colaborativa, tendo em vista o fortalecimento do processo de aquisição do conhecimento e o desenvolvimento escolar de alunos com deficiência intelectual e transtornos globais do desenvolvimento. Para a autora, as práticas pedagógicas desenvolvidas na escola podem se constituir em um caminho potente para garantir o acesso ao conhecimento por parte desses estudantes, na medida em que os apoios previstos ao trabalho realizado em sala de aula efetivamente funcionem. A garantia de condições de trabalho apropriadas, o apoio aos diferentes profissionais que atuam com crianças com deficiência e/ou transtornos, a formação continuada, bem como os recursos pertinentes aos processos de ensino e de aprendizagem são fundamentais para que 
a inclusão escolar ocorra.

A análise de estudos, como os apresentados, indica desafios e possibilidades na escolarização de crianças com autismo no ensino comum. Aponta, porém, que os processos de ensino e de aprendizagem ainda se constituem em desafios para muitos profissionais, especialmente em momentos de transição de uma etapa da educação básica para outra, de uma turma para outra, ou mesmo de substituição de professores. Esses desafios estendem-se, ainda, aos modos de interação e de inserção desses alunos na dinâmica educativa.

Estudos desenvolvidos por Padilha (2017) e Dainêz (2014) a respeito da educação escolar de alunos com deficiência, referenciados nos postulados de Lev Semenovich Vigotski, ${ }^{1}$ têm permitido problematizar o delineamento de meios auxiliares e caminhos alternativos nos processos de ensino e de aprendizagem desses estudantes. Como se configurariam esses meios auxiliares e caminhos alternativos na educação escolar desses alunos? Essa é a questão que este trabalho se propõe discutir.

Diante disso, nossa intenção é analisar as possibilidades de meios distintos e caminhos alternativos na intervenção pedagógica realizada em uma turma do primeiro ano do ensino fundamental que tem como um de seus alunos um menino com autismo. A opção por enfocar o início do ensino fundamental se deve aos desafios que perpassam a educação dessas crianças na passagem da educação infantil para esse nível de ensino - mudanças significativas ocorrem na vida escolar dessas crianças, demandando estudos e discussões acerca dos processos de ensino e de aprendizagem.

De forma a aprofundar a discussão sobre essa questão, do ponto de vista teórico e conceitual, bem como de implicações para a prática pedagógica, a seguir, serão feitos alguns apontamentos a respeito dos processos de aprendizagem e de desenvolvimento de crianças com deficiência a partir da perspectiva histórico-cultural.

\section{O desenvolvimento humano na abordagem histórico-cultural}

Tendo como pressuposto a base material e histórica da constituição do homem, Vygotski (1983, 1997), Luria e Yudovich (1985) e também Leontiev (1986) discutem o desenvolvimento das funções psicológicas superiores e dos processos mediados, ressaltando o papel do outro e da linguagem, bem como do ensino escolar na educação de crianças sem e com deficiência.
O desenvolvimento cultural implica a participação do outro, que se expressa nas relações sociais nas quais a criança é inserida desde o nascimento e que a constituem como pessoa: nós somos um agregado de relações sociais interiorizadas, afirma Vigotski (2000). Por meio das ações e das palavras dos outros, a partilha de concepções, modos de ser, de agir e de sentir progressivamente vai permitindo à criança a apropriação da herança cultural de gerações passadas. É nesse percurso que o substrato biológico que a constitui vai tomando, ele próprio, uma configuração cultural. A apropriação e o uso de signos propiciam a inter-relação entre as funções psíquicas, a ação intencional e o controle consciente da conduta: ao "[...] subordinar-se às ordens verbais do adulto, a criança adquire um sistema de instruções verbais e começa a utilizá-las gradualmente, para regular sua própria conduta" (LURIA; YUDOVICH, 1985, p. 13).

As palavras e as ações dos adultos - também elas parte da herança cultural - são transmitidas à criança por meio da educação, processo que permite a (re)constituição, em cada indivíduo singular, das operações mentais, dos conhecimentos e valores e do saber fazer adquiridos no transcorrer da história da humanidade (LEONTIEV, 1986). Cabe à educação escolar grande parcela dessa transmissão cultural, sobretudo no que diz respeito à elaboração conceitual dos alunos. A apropriação de conceitos científicos e de todos os processos psicológicos necessários à transição do pensamento concreto ao abstrato implica uma intencionalidade e sistematicidade que tem sido delegada à escola.

De forma contrária a perspectivas teóricas que desconsideram as possibilidades que o ensino escolar traz para o desenvolvimento infantil, enfocando as produções típicas do pensamento infantil, Vigotski (2009) chama a atenção para as possibilidades que se abrem ao avanço do pensamento da criança quando esta é colocada em situações de ensino sistemático e quando a ação educativa atua sobre processos psíquicos em desenvolvimento. Para o autor, "[...] só é boa aquela aprendizagem que passa à frente do desenvolvimento e o conduz" (VIGOTSKI, 2009, p. 332-333). Assim, destacam-se, como elementos centrais, a colaboração dos adultos - atuando sobre os processos psíquicos em desenvolvimento $-\mathrm{e}$ as possibilidades de imitação da criança, entendidas pelo autor como meio fundamental de interferência da aprendizagem sobre o desenvolvimento. Para Vigotski, as produções infantis que se delineiam por meio da 
imitação não têm um valor menor, pois revelam justamente os processos em via de amadurecimento na criança.

Como compreender o desenvolvimento da criança com deficiência ou transtornos diante desses pressupostos teóricos?

Vygotski (1997) afirma que o desenvolvimento do sujeito com deficiência segue o mesmo processo dos considerados sem deficiência, porém por caminhos alternativos. Para o autor, o desenvolvimento cultural "[...] é a principal esfera em que é possível compensar a deficiência. Onde não é possível avançar no desenvolvimento orgânico, abre-se um caminho sem limites para o desenvolvimento cultural" (VYGOTSKI, 1997, p. 187). ${ }^{2}$ Sendo assim, não é propriamente a deficiência que impossibilita o avanço nas formas superiores de pensamento, mas sim a maneira como essa deficiência é concebida e considerada nos investimentos dos adultos em relação à apropriação cultural por crianças e jovens com deficiência.

Quando se trata da educação para o aluno com deficiência ou transtornos, a proposta das escolas frequentemente permanece na construção de atividades diferentes daquelas previstas para os demais alunos - de modo geral, com o objetivo de trabalhar coordenação motora, cópia ou reconhecimento de letras, sílabas ou palavras descontextualizadas - reforçando o que esse aluno já sabe ou detendo-se na exercitação de funções elementares (CRUZ, 2009; SANTOS, 2012; DALLA VECCHIA, 2017).

Para a educação escolar desses alunos, Vygotski (1997) chama a atenção para a necessidade de desenvolver "meios especiais" e "caminhos distintos", quando necessário:

A criança cega ou surda pode alcançar o mesmo desenvolvimento de um aluno normal, porém as crianças com deficiência alcançam de um modo distinto, por um caminho distinto, com outros meios, e para o professor é importante conhecer a peculiaridade do caminho pelo qual se deve conduzir a criança (VYGOTSKI, 1997, p.17, grifos do autor, tradução nossa) ${ }^{3}$

$\mathrm{O}$ autor chama a atenção para meios auxiliares, como o sistema Braille ou a "escrita no ar" para os surdos, como forma de possibilitar a crianças cegas e surdas o desenvolvimento cultural. No entanto, como pensar esses meios de caminhos distintos para crianças com deficiência mental ou alguns tipos de transtornos? Apesar de Vigotski não dirigir seus estudos diretamente à temática do autismo, seus princípios sobre o papel do outro no desenvolvimento humano e o lugar do ensino na configuração das funções psicológicas superiores contribuem para analisarmos possibilidades de aprendizagem e de desenvolvimento desses sujeitos. Dessa forma, indagamos sobre o que seriam esses meios distintos e caminhos alternativos na educação escolar dessas crianças e nos propomos discutir suas possibilidades de configuração na intervenção pedagógica realizada em uma turma do primeiro ano do ensino fundamental que tem como um de seus alunos um menino com autismo.

\section{O método e a pesquisa de campo}

Este artigo constitui-se em parte de uma pesquisa mais ampla que visou a investigar o movimento de construção de caminhos alternativos na prática pedagógica desenvolvida com crianças com autismo em turmas do $1^{\circ}$ ano do ensino fundamental. Para isso, orientou-se pela pesquisaação como suporte metodológico, por considerar que essa abordagem permite e exige do pesquisador implicar-se com a realidade vivenciada no espaço a ser pesquisado, com a estrutura social em que está inserido, ao mesmo tempo em que "[...] não propõe um trabalho sobre os outros, mas, e sempre, com os outros, não excluindo os sujeitos autores da pesquisa" (BARBIER, 2004, p. 14).

A opção pela pesquisa-ação implicou diferentes formas de envolvimento do pesquisador com o campo de investigação e a participação em ações distintas de forma a colaborar com as práticas educativas desenvolvidas pelos profissionais da escola. No entanto, considerando os objetivos deste trabalho, vamos nos deter apenas em uma das turmas que fizeram parte do estudo e enfocaremos aspectos dos processos de ensino e de aprendizagem em que estava envolvido um menino com autismo, os quais contribuem para a discussão acerca dos meios e caminhos alternativos na escolarização de crianças com autismo.

O caráter teleológico da escola, a intencionalidade e a sistematicidade da ação educativa, bem como o acúmulo de reflexões e práticas sobre a intervenção pedagógica concedem a essa instituição um potencial inigualável na promoção de um ensino fecundo, conforme defende Vigotski (GÓES, 2008). Tendo como principal atribuição a ampliação da formação humana dos alunos, sobretudo no que diz respeito à elaboração conceitual, a escola deve promover, ao mesmo tempo, condições que resultem no progressivo 
avanço de seu desenvolvimento. É nessa perspectiva que esse espaço se constitui em um ambiente propício ao estudo de aspectos do desenvolvimento infantil, em consonância com algumas proposições de Vygotski (1983) acerca de método.

Para o autor, o estudo do desenvolvimento infantil deve orientar-se por uma perspectiva que coloque em foco o movimento, a historicidade do processo, revelando suas múltiplas determinações. Em contraposição a uma visão que se detém em características externas, aparentes do fenômeno investigado e que se funda na descrição, Vygotski (1983) propõe uma análise das formas superiores de pensamento, que se fundamenta tanto nas manifestações externas do fenômeno, como em sua gênese e em suas relações dinâmico-causais.

Os parcos relatos de pesquisa que são apresentados nas análises do autor apontam uma perspectiva metodológica que tem como princípio a reconstrução de um determinado processo psicológico dos estágios que o compõem. Essa reconstrução ocorre por meio da realização de experimentos cuidadosamente planejados, nos quais se coloca a criança diante de tarefas que excedam suas possibilidades de realização e se vai, gradativamente, inserindo meios auxiliares que permitam a ela o sucesso na execução da tarefa.

Assim, o experimento possibilita analisar o caminho pelo qual recursos auxiliares se interpõem entre a criança e a tarefa, orientando sua ação. Tendo em vista que o uso desses recursos, como forma de regular a própria conduta, é um processo que caracteriza as funções psíquicas superiores, a reconstrução do percurso pelo qual esse processo ocorre em uma dada esfera do desenvolvimento permite o acesso à sua historicidade, ao movimento que o caracteriza com seus múltiplos determinantes.

Conforme ressalta Vygotski (1983) e Vygotski e Luria (2007), o que caracteriza esses recursos auxiliares é o fato de se constituírem como signos, orientando-se para a atividade intrapsíquica e, nesse contexto, a análise aponta como, paulatinamente, a criança vai se apropriando e significando estímulos que inicialmente eram indiferentes para ela, de tal forma que estes passem a regular suas ações.

Desse modo, é possível delinear pontos de confluência entre essa perspectiva de investigação do desenvolvimento infantil e os meandros da intervenção pedagógica, para que se possa dessa forma acompanhar o percurso pelo qual se criam as condições necessárias à apropriação de conhecimentos pelos alunos; isso implica, em parte, identificar tanto os meios pelos quais essa intervenção atua sobre suas funções psicológicas, como a maneira como são afetados por esses recursos e as possibilidades de desenvolvimento que eles propiciam.

Considerando o modo singular com que muitas crianças com autismo se relacionam com as atividades escolares e os desafios que perpassam a intervenção pedagógica, entendemos que a escola se apresenta como um espaço altamente propício tanto ao estudo do desenvolvimento dessas crianças, como de práticas educativas que lhes favoreçam a apropriação de conhecimentos.

Diante disso, enfocaremos uma turma de primeiro ano do ensino fundamental, composta por 25 alunos, entre eles, João, criança de seis anos, com autismo. Participaram também da pesquisa uma professora regente contratada temporariamente para atuar com a turma, a docente de educação especial e uma estagiária. A professora de educação especial também era contratada, demonstrava ser experiente na área da deficiência intelectual e acompanhava, entre outros alunos, aqueles com autismo, matriculados naquela unidade de ensino. Outra participante do estudo, a estagiária do Curso de Pedagogia, estava no $5^{\circ}$ período e era iniciante no estágio não obrigatório.

A pesquisa de campo foi realizada no período de janeiro a dezembro de 2015. Os procedimentos para a coleta de dados foram: estudo de documentos arquivados na escola e disponibilizados pela Secretaria Municipal de Educação; observação em contexto; entrevistas semiestruturadas com roteiro; participação em reuniões (planejamentos, Conselhos de Classe, encontros de formação na escola e oferecidos pela Secretaria Municipal de Educação, dentre outros). O registro do material coletado foi feito por meio de diário de campo, fotografias e filmagens.

\section{Resultados e discussão}

João, criança com autismo, que frequentou a educação infantil desde os dois anos de idade, estava matriculado no primeiro ano do ensino fundamental. Era o primogênito de uma família de descendência japonesa. Seu irmão mais novo havia nascido no final de 2014. Seus pais moravam em casa própria e trabalhavam em um comércio da família. Apesar de sua fala pouco articulada, ele se comunicava oralmente para narrar fatos que aconteciam cotidianamente em sua vida; para informar o que queria fazer, do que gostava, algumas vezes 
repetindo frases e palavras. Interagia pouco com as outras crianças, demonstrava dificuldade em compartilhar brinquedos e outros objetos, além de expressar interesses restritos, como o uso de lápis amarelo, massa de modelar e CD-ROM que ele dispunha na carteira ou na cadeira, e executava movimentos típicos de uma pessoa tocando bateria.

Nesse contexto, na escola campo deste estudo, a busca por meios auxiliares e caminhos alternativos para os processos de ensino e de aprendizagem de João foram se delineando aos poucos e por caminhos muitas vezes tortuosos, indicando a necessidade de discussão de questões diferenciadas. Entre essas questões, destacamos: a entrada de João na escola e o percurso do portão à sala de aula; a entrada na sala de aula e os processos de ensino e de aprendizagem; as possibilidades de meios auxiliares e vias alternativas.

\section{A entrada na escola e o percurso do portão à sala de aula}

Inicialmente, João não queria permanecer na escola. Chorava muito no portão e não entrava na sala de aula. As ações reiteradas da criança de entrelaçar os braços no portão da escola, chorar e pedir para "ir para casa" tornava o dia escolar cada vez mais desafiador. Nas primeiras semanas, ele não respondia a nenhuma tentativa feita por profissionais da escola para tirá-lo daquela condição. Sua linguagem era marcada por frases curtas e repetitivas e as tentativas de diálogo com ele não apresentavam êxito.

Por outro lado, na educação infantil, a família informou que tudo ocorria de acordo com o planejado pelas professoras. João participava das atividades, das brincadeiras e de todos os momentos com o grupo. Ele parecia se ressentir da alteração brusca de espaços educativos.

Não temos notícias de ações realizadas de forma a preparar a criança para a transição do centro de educação infantil para a escola de ensino fundamental. Entretanto, a dificuldade de inserção em novos ambientes é um aspecto mencionado em diferentes estudos que abordam a prática educativa com crianças com autismo (CRUZ, 2009; SANTOS, 2012; DALLA VECCHIA, 2017). De modo geral, ambientes novos, pessoas desconhecidas ou mudanças no espaço causam incômodo e sofrimento a essas crianças, expressos por meio de crises de choro ou outras manifestações não verbais. Dessa forma, esses estudos alertam para a necessidade de uma atenção especial à criança nesses momentos, preparando-a para as mudanças e novas experiências.
O percurso do aluno do portão à sala de apoio, da sala de apoio ao recreio e à sala de aula demandou um trabalho colaborativo entre os profissionais da escola (EFFGEN, 2017), a ação coletiva de maneira a conhecer a criança, identificando seus interesses, necessidades, a forma como estava elaborando a entrada na nova escola e possibilidades de meios distintos para inseri-la na dinâmica educativa de sua turma.

O primeiro movimento foi ir do portão à sala de apoio, o que ocorreu aos poucos e a partir de um trabalho paciente de convencimento da criança pelos professores. Em um dos dias em que estava chorando no portão, além de repetir que queria ir embora, João disse: "Quero lápis amarelo!". Rapidamente uma professora chamou João para a sala de apoio onde havia lápis de cor, inclusive os amarelos. Diante dos lápis, a criança segurou um em cada mão e começou a repetir movimentos no ar que lembravam baquetas batendo em uma bateria. ${ }^{4}$ Permaneceu naquela sala o dia todo repetindo essa ação, não aceitando mais nada que lhe era oferecido, somente seu lanche. Às vezes ia ao banheiro.

Por outro lado, o deslocamento da criança para esse espaço gerou novos desafios. Foram necessárias diversas negociações para que João não permanecesse o tempo todo na sala de apoio e realizando o mesmo movimento com os lápis de cor amarela: houve um esforço de deixar nítido para ele que havia tempos e espaços definidos na escola, atividades a serem realizadas, brincadeiras a serem aprendidas e conhecimentos para serem apropriados.

$\mathrm{O}$ percurso da sala de apoio à sala de aula foi tão lento quanto o de tirá-lo do portão. Uma vez que conheceu esse espaço, João encaminhava-se para lá assim que chegava à escola. Não entrou na sala de aula até o final do mês de março, quando começou a frequentá-la. Como parecia estar mais calmo na sala de apoio, após algum tempo, os professores começaram a prepará-lo para ir para a sala de aula comum. Foi convidado pela professora de educação especial por algumas vezes para conhecer os novos colegas, mas ele continuava resistente em sair da sala de apoio e demonstrava querer permanecer ali, dizendo "Não quero" ou iniciando novos momentos de choro.

Preocupada com a participação de João nas atividades da escola e em diálogo com a equipe, a família sugeriu levá-lo diretamente para a sala assim que chegasse à escola. Novas negociações foram realizadas com João. Foi explicado a ele que, ao chegar à escola, iria direto para a sua sala de aula e que somente depois poderia ir para a sala de apoio. 
Nos primeiros dias dessa nova organização, ele ficou muito angustiado. Mal acabava de entrar na sala de aula, já saía para ir para à sala de apoio chorando, gritando e pedindo lápis amarelo e CDs - materiais que o aluno aprendeu a encaixar em cadeiras, simulando pratos de uma bateria; em seguida, o movimento repetitivo se iniciava.

Ele manteve esse comportamento por algumas vezes, até que um dia, tentando uma nova negociação, a estagiária disse que só the daria o material, se ele parasse de chorar e ficasse pelo menos a primeira aula na sala com os demais alunos, aprendendo o que a professora estava ensinando. João persistiu chorando por mais um pouco, mas aceitou o combinado. Então, a estagiária deu o material que o aluno queria, sentou-se ao seu lado e ficou observando o que João fazia enquanto a professora estava à frente da turma conduzindo a aula.

Esse foi o início da permanência da criança na sala regular, às margens do que estava acontecendo nesse espaço, mas presente, algumas vezes repetindo o que a professora dizia, ou apenas olhando o que os outros estavam fazendo. Entretanto, esse momento foi fundamental para a inserção da criança na dinâmica educativa da turma.

\section{A entrada na sala de aula e os processos de ensino e de aprendizagem}

Todavia, a entrada da criança na sala de aula não significou um envolvimento imediato dela nas atividades escolares. Incertezas, desconhecimentos, tentativas pouco frutíferas e um aparente descrédito nas possibilidades de João envolver-se nas atividades junto com as outras crianças compuseram o movimento de inserção da criança no trabalho desenvolvido em sala de aula. A situação relatada a seguir permite delinear o cenário de sua entrada na sala de aula:

A professora de Educação Especial, Ângela, chegou à sala de João no momento em que a professora regente havia iniciado uma atividade em folha xerocada sobre o folclore com a turma. João estava sem nenhuma proposta. Havia dois lápis encaixados nas costas da cadeira da frente que o aluno pegava, fazia movimento de batidas de baqueta em uma bateria e devolvia novamente os lápis aos buracos na cadeira. Ângela pediu uma folha à professora e dirigiu-se ao aluno, dizendo:

- Vamos fazer o dever e depois você brinca com a "baqueta", combinado, João?
- Combinado. [Ele respondeu].

- Vamos fazer uma atividade que está todo mundo fazendo. [Ele olhou para o lado e observou os outros alunos realizando uma tarefa, cada um em sua mesa, concentrados na proposta. Em seguida, começou a participar, orientado pela professora].

A configuração da sala de aula descrita se repetia nas primeiras semanas que se seguiram à entrada de João nesse espaço: a professora regente desenvolvia a aula diante das crianças sem deficiência; João sentava-se em um canto da sala, ao lado da estagiária. Costumava se recusar a realizar as atividades que lhe eram propostas, distraindo-se com sua "bateria". A estagiária tentava auxiliá-lo na realização das tarefas que a professora apresentava aos demais alunos ou se encarregava de selecionar algumas atividades específicas para ele. Uma vez que ele não se envolvia na dinâmica educativa como seus colegas, a professora regente considerava difícil encontrar formas alternativas de inseri-lo nas atividades, de criar condições para que ele aprendesse o que era abordado em sala e, consequentemente, de avaliá-lo.

A escolarização de alunos com autismo atualmente tem demandado um conjunto de apoios, os quais são previstos na legislação, mas, em muitos casos, ainda são implementados de forma precária. A pesquisa realizada chama a atenção para os apoios materiais para a inclusão, como a sala de recursos multifuncionais, a formação continuada e o tempo para estudo e planejamento coletivo. Resultados semelhantes são encontrados nos estudos de Cruz (2009), Chiote (2011), Effgen (2017) e Dalla Vecchia (2017) que apontam a necessidade de criação de condições organizacionais para a inclusão de crianças com autismo, o papel do trabalho colaborativo na escola e o investimento na formação do professor.

A presença de mais um professor em sala tem sido requisitada por professores regentes de turmas com alunos com autismo e reiterada em estudos sobre o tema (EFFGEN, 2017; DALLA VECCHIA, 2017). Na situação descrita, constatamos que a entrada da professora de educação especial na sala altera a dinâmica estabelecida. $\mathrm{O}$ aparente alheamento do aluno, em relação ao que ocorria na sala, é interrompido quando a professora, dirigindo-se especificamente a ele e orientando sua atenção, levao a observar o que os colegas estavam fazendo e, ainda, orientando sua atenção, ela o conduz na realização da tarefa.

A atenção é apontada por Vygotski e Luria 
(2007) como uma função especial, dado seu papel no desenvolvimento de outras funções. Para os autores, a apropriação da linguagem cria condições para o domínio da atenção e, com isso, reorganizações no campo perceptivo da criança, "[...] creando nuevos centros estructurales de la situación percebida" (VYGOTSKI, LURIA, 2007, p. 44), os quais, em articulação com diferentes funções, vão congregando elementos de diferentes ordens, que permitem a atenção a uma configuração complexa, que inclui as experiências vividas, a elaboração conceitual e a dimensão socioafetiva.

A continuidade do episódio nos possibilita identificar um pouco do que João já sabia em relação ao conteúdo abordado, mas que, talvez pela dificuldade de coordenar a demanda de atenção de João com a dos demais alunos, a professora regente parecia desconhecer.

- É um caça-palavras - [disse Ângela] - você conhece os personagens?

[Ele ficou quieto. Ela mesma respondeu].

- Esse é o Saci. Ele tem uma perna só, mas está dando para ver direito, né? [apontando para a imagem do Saci na folha com o dedo]. Olha o nome dele aqui. Começa com que letra? [mostrando a palavra escrita na folha].

$-S$.

- E depois vem o quê?

[João foi respondendo letra a letra a cada pergunta da professora Ângela, formando a palavra SACI]. (DIÁRIO DE CAMPO, 5-62015).

No diálogo iniciado pela professora Ângela com o aluno, percebemos que houve um combinado para que ele realizasse a tarefa e depois pudesse se dedicar à sua atividade preferida. A relação de confiança estabelecida com essa professora na sala de apoio e a prática de negociar com ele algumas atividades favoreceram a realização da tarefa na sala de aula. A constatação de que João estava sem a folha de atividade e a solicitação do material à professora regente foi o primeiro passo para inseri-lo na dinâmica educativa de sua turma. Com a folha xerocada em mãos, chamar a sua atenção para o que as demais crianças estavam fazendo também ajudou o aluno a se situar em meio aos colegas, observar o que estavam realizando e o que era esperado dele também.

Situar-se em meio a um grupo, reconhecerse como parte desse grupo e engajar-se nas mesmas tarefas realizadas pelos colegas costuma ser um processo lento e, por vezes, tenso, para alguns alunos com autismo, que apresentam certa tendência ao isolamento e aos interesses restritos (SANTOS, 2012). Dessa forma, uma atenção especial a isso tem sido necessária na intervenção educativa com esse aluno, de modo a transpor a barreira que dificulta a interação com os outros e ampliar seu leque de interesses.

Ângela apostou nas possibilidades de aprender de João e buscou formas de levá-lo a realizar a mesma tarefa que as demais crianças. Com isso, ela constatou que ele reconhecia as letras do alfabeto, mas precisava de auxílio para entender a atividade e orientação de sua atenção para fazer o caça-palavras. O investimento da professora na consolidação de conhecimentos em processo de desenvolvimento no aluno por meio da colaboração na realização da tarefa - demonstrando como fazer e fazendo com a criança - permitiu a João mostrar o que já sabia, aprender a realizar uma atividade nova e conclui-la, como os demais colegas.

Vigotski (2009) chama a atenção para a zona de desenvolvimento iminente ${ }^{5}$ e para o papel da imitação no processo de elaboração conceitual do aluno, indicando, a nosso ver, que as possibilidades de caminhos alternativos na educação escolar de crianças com deficiência necessariamente implicam a consideração desses dois componentes. Realizar tarefas escolares em colaboração com o outro é um passo fundamental para a apropriação dos conhecimentos e atos de pensamento necessários à execução dessas atividades de forma independente $\mathrm{e}$ voluntária.

A colaboração de outras crianças também foi ressaltada neste estudo, de forma a permitir a João perceber-se como parte da turma, interagir com os colegas e brincar com eles. As peculiaridades do desenvolvimento da criança com autismo, como o pouco contato visual com o outro, a resistência em permanecer no grupo, o choro constante e os interesses restritos, podem não favorecer sua inserção na dinâmica da turma, demandando dos professores uma atenção especial à relação estabelecida entre essa criança e seus pares. Conforme apontam Siqueira (2011) e Chiote (2011), as ações das crianças junto ao aluno com autismo podem servir de referência e incentivo à sua participação nos diferentes tempos e espaços da escola.

Entretanto, um episódio observado envolvendo João e a estagiária permite problematizar os modos de colaboração, que, em certos momentos, podem ser pouco convencionais no ensino de estudantes com deficiência, considerando as formas 
como historicamente as metodologias de ensino e de avaliação têm se constituído.

A professora entregou aos alunos uma folha xerocada que continha um texto e questões para serem respondidas. Ao chegar perto de João, ele disse: "Folha não, ler não". Então a estagiária pegou a folha e disse: "Não vou ler para você, não, vou ler para mim”. Virou a folha para o seu lado e começou a ler o texto. João olhava meio de lado para o que ela estava lendo. Quando terminou a leitura do texto, ela começou a ler, em voz alta ainda os enunciados das perguntas sobre o texto. À medida que ela fazia as perguntas, João ia respondendo oralmente. Respondeu a todas as perguntas (DIÁRIO DE CAMPO, 16-11-2015).

Um aspecto ressaltado por estudos sobre a escolarização de alunos com autismo diz respeito à resistência em realizar tarefas escolares e à tendência de seguir sempre a mesma rotina, frequentando os mesmos espaços e realizando indefinidamente a mesma atividade (SIQUEIRA, 2011; CHIOTE, 2011; EFFGEN, 2017; DALLA VECCHIA, 2017). No episódio relatado, diante de uma folha com um texto e questões para responder, João logo diz: "Folha não, ler não". Quais são as possibilidades de ação diante dessa recusa? O que se delinearia como caminho alternativo diante de uma atividade que tinha como objetivo que os alunos lessem e escrevessem?

A estagiária teve a iniciativa de ler em voz alta, ao lado da criança. Essa estratégia não implicava a leitura pela criança, mas permitia aproximá-la da dinâmica educativa vivenciada pela turma. João não leu nem escreveu, mas outros processos psicológicos foram mobilizados durante a leitura da estagiária, permitindo a ele apropriar-se do conteúdo do texto e responder adequadamente às questões sobre ele. A atenção ao que era lido; o acompanhamento da sequência do texto; os processos de análise, síntese e comparação, entre outros, implicados na compreensão e reconstrução desse texto (um trabalho de memória) são ações mobilizadas pela criança na realização possível da tarefa naquele momento. Uma atividade que parecia ter sentido para João, ainda que fosse desenvolvida com a intermediação da estagiária.

Pode-se dizer, nesse caso, que uma estratégia alternativa de realização da tarefa foi implementada pela estagiária, a qual permite atender, em parte, ao objetivo da professora regente. Esse procedimento possibilitou contornar a resistência da criança e mantê-la na dinâmica da sala, embora ainda não seja a partir de suas ações de ler e escrever. Se considerarmos a estratégia como parte de possíveis caminhos alternativos de ação educativa, podemos dizer que ela apresenta perspectivas interessantes, mas, ao mesmo tempo, talvez também limites no que diz respeito às funções psicológicas envolvidas e ao tempo de apropriação do conhecimento abordado João não leu nem escreveu.

Por outro lado, do ponto de vista dos processos psicológicos envolvidos, o episódio parece sugerir também vias consideradas pouco convencionais de percursos de pensamento. Embora a criança se recusasse a realizar atividades de leitura e escrita, no processo inicial de alfabetização, ela diferencia letras e números, reconhece letras do alfabeto, compreende a estrutura de um texto escrito, traça palavras usando letras, realiza leitura de palavras e frases com orações simples.

\section{As possibilidades de meios auxiliares e caminhos alternativos}

Os apontamentos feitos sobre o início da escolarização de João no ensino fundamental trazem elementos que permitem problematizar e aprofundar a discussão acerca do que seriam os meios auxiliares e os caminhos alternativos na educação escolar de alunos com autismo e também deficiência mental.

A abordagem de possíveis meios auxiliares e caminhos alternativos na escolarização desses estudantes pode levar aquele que tem uma visão superficial da teoria à expectativa de encontrar técnicas que serão aplicadas ou recursos que serão utilizados - sem necessariamente considerar o aluno e o contexto em que se delineiam os processos de ensino e de aprendizagem -, os quais produzirão respostas imediatas e adequadas por parte desses estudantes. $\mathrm{O}$ estudo realizado indica e/ou reitera que essa interpretação não é pertinente.

Diferentes elementos entram em jogo na configuração de um contexto propício aos processos de ensino e de aprendizagem do aluno com autismo, na escola regular, mas eles não se distinguem por uma "técnica nova" e sim por reorganizações do planejamento previsto para os estudantes sem deficiência, com pequenas alterações nos objetivos, conteúdo e procedimentos. Encontrar algumas estratégias alternativas para vencer a resistência da criança e orientar de forma intensiva sua atenção foi um caminho utilizado pela equipe pedagógica, o qual se delineou em um constante falar por ela e com ela, fazer por ela e com ela quando se evidenciavam seus limites para elaborar, comunicar e realizar uma tarefa sozinha, como destaca Vigotski (2009). 
Podemos dizer que este estudo é corroborado pelas pesquisas realizadas por Padilha (2000), Chiote (2011) e Oliveira, Victor e Chicon (2016). Esses trabalhos analisam intervenções pedagógicas na ação educativa com uma jovem com deficiência mental e duas crianças com autismo, colocando em foco as interações estabelecidas, o reconhecimento desses sujeitos como pessoas plenamente capazes de avançar em seu desenvolvimento por meio de situações de aprendizagem cuidadosamente planejadas, o desenvolvimento de modo variado e recorrente de práticas que possibilitassem a elas a consciência de si e o domínio da própria conduta. Nesse percurso, destacam-se: a orientação sistemática e intensiva da atenção desses sujeitos nas tarefas propostas; o paciente esforço de situar sua ação no contexto das práticas sociais e uso convencional de objetos; a significação de suas próprias ações e sentimentos e as ações dos outros; a (re)constituição orientada de fatos e experiências vividas em sua relação com o presente e o futuro; o estabelecimento de relações "lógico-abstratas" e o controle da vontade.

Diante disso, o que pode ter se configurado como alternativo, no início do processo de escolarização de João no ensino fundamental, parece ter relação com uma planejada, recorrente e intensiva "alimentação do meio", como aponta Vygotski (1997, p. 114): ${ }^{6}$

O desenvolvimento insuficiente das funções superiores está relacionado com o desenvolvimento cultural insuficiente da criança deficiente mental, com sua exclusão do meio cultural, da "nutrição" do meio. Devido a essa insuficiência, essa criança não experimentou oportunamente as influências do meio circundante. Por causa disso, sua deficiência se acumula, se acumulam as particularidades negativas e as complicações complementares na forma de um desenvolvimento social insuficiente de uma negligência pedagógica.

Assim, o descrédito nas possibilidades de desenvolvimento de alunos com autismo, a não consideração de suas peculiaridades no planejamento educativo, a não compreensão ou falta de condições de atender às suas demandas em termos de atenção intensiva e consideração de seu tempo próprio de se engajar na dinâmica educativa da turma e de aprender dificultam a identificação do que se poderia chamar de alternativo na prática pedagógica com um aluno específico, em um momento próprio de seu desenvolvimento. Embora seja possível antecipar algumas peculiaridades de crianças com autismo, a prática educativa indica que cada uma é única e nem sempre as ações que repercutem em possibilidades de avanço para uma se concretizam no trabalho implementado com outra criança. Vencer a "negligência pedagógica" e investir em ações diversificadas, em colaboração intensiva com a criança - e significativas para ela -, parece ser a via para tracionar seu desenvolvimento cultural.

\section{Considerações finais}

Constatamos que, no caso de João, uma criança com autismo que verbaliza, as ações diferenciadas dos profissionais e da estagiária orientaram-se em duas direções. A primeira diz respeito aos aspectos organizativos da escola, que procurava garantir os apoios necessários ao professor regente e à criança, tendo em vista sua aprendizagem: estudo e planejamento coletivo, trabalho colaborativo e a presença de uma estagiária na sala. Embora essas ações não estejam diretamente relacionadas com os processos de ensino e de aprendizagem, elas se colocam como condições necessárias à criação de oportunidades alternativas e meios auxiliares ao aprendizado de crianças com transtornos ou deficiência.

A segunda dimensão a ser ressaltada diz respeito a ações voltadas especificamente para os processos de ensino e de aprendizagem. A atuação da equipe pedagógica indica como relevante na escolarização de João: as constantes negociações com ele, acompanhadas de um paciente trabalho de convencimento; o esforço de explicitar para ele tanto a rotina da escola e o que era esperado dele em seu lugar de aluno como o seu pertencimento a uma turma; o incentivo à colaboração dos colegas de forma a inseri-lo nas atividades e brincadeiras; o trabalho permanente, intensivo e por diversas vias de orientação de sua atenção e condução na realização das tarefas escolares; e uma atenção ao seu tempo próprio de inserção no ambiente escolar, de constituir-se como aluno e, nesse percurso, desenvolver certo domínio da própria conduta que lhe permita a realização das atividades escolares com independência.

Meios especiais e caminhos alternativos na educação escolar de crianças com autismo parecem se configurar em um contexto em que os professores reconhecem as possibilidades educativas desses estudantes, ao mesmo tempo em têm condições apropriadas de estudo, de planejamento e de construção de um trabalho colaborativo, de maneira 
a subsidiar a ação educativa coletiva em prol do aprendizado dessa criança junto com as demais.

\section{Notas}

1 Neste trabalho o sobrenome do autor será grafado como Vigotski. Entretanto, quando se fizer menção a uma obra cuja grafia for diferente, será considerada a forma de escrita da obra referenciada.

2 " $[. .$.$] es la esfera fundamental donde resulta posible$ la compesnación de la insuficiencia. Donde resulta imposible um desarrollo orgânico ulterior, se abre ilimitadamente el camino del desarrollo cultural" (VYGOTSKI, 1997, p.187).

3 "El niño ciego o sordo puede lograr en el desarrollo lo mismo que el normal, pero los niños con defecto lo logran de distinto modo, por un camino distinto, com otros médios, y para el pedagogo es importante conocer la peculiaridad del camino por el cual debe conducir al niño. La clave de la peculiaridad la brinda la ley de transformación del menos del defecto en el más de la compensación" (VYGOTSKI, 1997, p.17).

4 A bateria é um conjunto de tambores (de diversos tamanhos e timbres) e de pratos colocados de forma conveniente com a intenção de serem percutidos por um único percussionista, denominado baterista, geralmente, com o auxílio de um par de baquetas, vassourinhas ou bilros, embora no caso de alguns executantes, possam também ser usadas as próprias mãos.

5 Apesar de, na obra "A construção do pensamento e da linguagem", a tradução indicar o termo zona de desenvolvimento imediato, neste trabalho, optamos por utilizar o termo zona de desenvolvimento iminente, por considerar mais pertinente a tradução de Prestes (2012), que argumenta que, mais do que ressaltar a questão temporal, o conceito utilizado por Vigotski remete às possibilidades iminentes de desenvolvimento da criança.

6 "El desarrollo incompleto de las funciones superiores está ligado al desarrollo cultural incompleto del niño mentalmente retrasado, a su exclusión del ambiente cultural, de la 'nutrición' ambiental. A causa de la insuficiencia, no sintió oportunamente la influencia del ambiente circundante, a consecuencia de lo cual su retraso se acumula, se acumulan las características negativas, las complicaciones adicionales en forma de un desarrollo social incompleto, de uma negligencia pedagógica" (VYGOTSKI, 1997, p.144).

\section{Referências}

ANJOS, A. R. Cultura lúdica e infância: contribuições para a inclusão da criança com transtorno global do desenvolvimento. 2013. $173 \mathrm{f}$. Dissertação (Mestrado em Educação) - Programa de Pós-Graduação em Educação, Universidade Federal do Espírito Santo, Vitória, 2013.

BARBIER, R. A pesquisa-ação. Tradução de Lucie Didio,v.3, Brasília: Liber Livro Editora, 2004.

CHIOTE, F. de A. B. A mediação pedagógica na inclusão da criança com autismo na educação infantil. 2011. 188 f. Dissertação (Mestrado em Educação) - Programa de Pós-Graduação em Educação, Universidade Federal do Espírito Santo, Vitória. 2011.

CORREIA, H. C. A inclusão da criança com autismo em uma escola de educação infantil. 2012. $186 \mathrm{f}$.

Dissertação (Mestrado em Educação) - Programa de Pós-Graduação em Educação, Universidade Federal do Espírito Santo, Vitória, 2012.

CRUZ, T. S. U. R. Acompanhamento da experiência escolar de adolescentes autista no ensino regular. 2009. 174 f. Dissertação (Mestrado em Educação) - Programa de Pós-Graduação em Educação, Universidade Metodista de Piracicaba, Piracicaba, 2009.

DAINÊZ, D. Constituição humana, deficiência e educação: problematizando o conceito de compensação na perspectiva histórico-cultural. 2014. 125 f. Tese (Doutorado em Educação) - Programa de Pós-Graduação em Educação, Universidade Estadual de Campinas, Campinas; SP, 2014.

DALLA VECCHIA, C. C. S. Práticas pedagógicas no ensino de crianças com autismo na perspectiva da educação inclusiva: um olhar do professor. 2017. 90f. Dissertação (Mestrado em Educação) Programa de Pós-Graduação em Educação, Universidade Estadual do Centro-Oeste, Guarapuava, 2017.

EFFGEN, A. P. S. Escolarização de alunos com deficiência intelectual e transtornos globais do desenvolvimento: processos de mediação pedagógica no cotidiano escolar. 2017. 235 f. Tese (Doutorado em Educação) - Programa de Pós- 
Graduação em Educação, Universidade Federal do Espírito Santo, Vitória, 2017.

GÓES, M. C. R. A aprendizagem e o ensino fecundo: apontamentos na perspectiva da abordagem histórico-cultural. In: PERES, E. et al. (Org.). Trajetórias e processos de ensinar e aprender: sujeitos, currículo e cultura. (trabalhos do XIV Endipe, 2008) Porto Alegre: EDIPUCRS, 2008. p. 414-426.

LEONTIEV, A. O desenvolvimento do psiquismo. Inserir edição. Lisboa: Livros Horizonte, 1986.

LURIA, A. R.; YUDOVICH, F. I. Linguagem e desenvolvimento intelectual na criança. $2^{\mathrm{a}}$ edição. Porto Alegre: Artes Médicas, 1985.

OLIVEIRA, I. M.; VICTOR, S. L.; CHICON, J. F. Montando um quebra-cabeça: a criança com autismo, o brinquedo e o outro. Revista Cocar, Belém: Programa de Pós-Graduação Educação em Educação da UEPA, v. 10, n. 20, p. 73 a 96, ago./dez. 2016. Disponível em: <http://páginas.uepa.br/seer/index.php/cocar>. Acesso em: 21 out. 2017.

PADILHA, A. M. L. Práticas educativas: perspectivas que se abrem para a educação especial. Educação \&Sociedade, ano 21, n.71, p.197-219, 2000.

Desenvolvimento psíquico e elaboração conceitual por alunos com deficiência intelectual na educação escolar. Rev. Bras. Ed. Esp., Marília, v. 23, n.1, p. 9-20, jan./mar. 2017.

RAMOS, F. do V. C. Alunos com transtornos globais do desenvolvimento: da categoria psiquiátrica à particularidade do caso a caso nos processos de inclusão escolar. 2012. $190 \mathrm{f}$.

Dissertação (Mestrado em Educação) - Programa de Pós-Graduação em Educação: conhecimento e inclusão social, Universidade Federal de Minas Gerais, Belo Horizonte, 2012.

SALGADO, A. M. Impasses e passos na inclusão escolar de crianças autistas e psicóticas: o trabalho do professor e o olhar para o sujeito. 2012. $172 \mathrm{f}$. Dissertação (Mestrado em Educação) - Programa de Pós-Graduação em Educação, Universidade Federal do Paraná, Curitiba, 2012.

SANTOS, E. C. Entre letras e linhas de Rafael: estudo sobre a escolarização de uma criança com autismo no ensino comum. 2012. 191 f. Dissertação (Mestrado em Educação) - Programa de PósGraduação em Educação, Universidade Federal do Espírito Santo, Vitória, 2012.

SANTOS, R, V. A escolarização de crianças com transtorno do espectro autista: uma possibilidade de emancipação. 2016. 186 f. Dissertação (Mestrado em Educação) - Programa de Pós-Graduação em Gestão e Práticas Educacionais, Universidade Nove de Julho, 2016. Disponível em:

$<$ https://bibliotecatede.uninove.br/bitstream/tede/15 65/2/R\%C3\%A9gia\%20Vidal\%20dos\%20Santos.pd f>. Acesso em: 12 jun. 2018.

SILVA, E. C. S. A prática pedagógica na inclusão educacional de alunos com autismo. 2011. $166 \mathrm{f}$.

Dissertação (Mestrado em Educação) - Programa de Pesquisa e Pós-Graduação em Educação,

Universidade Federal da Bahia, Salvador, 2011.

SIQUEIRA, M. F. Educação Física, autismo e inclusão: ressignificando a prática pedagógica. 2011. 129 f. Dissertação (Mestrado em Educação Física) - Programa de Pós-Graduação em Educação Física, Universidade Federal do Espírito Santo, Vitória, 2011.

VASQUES, C. K. Alice na biblioteca mágica: uma leitura sobre o diagnóstico e a escolarização de crianças com autismo e psicose infantil. 2008. $185 \mathrm{f}$. Tese (Doutorado em Educação) - Programa de PósGraduação em Educação, Universidade Federal do Rio Grande do Sul, Porto Alegre, 2008.

VYGOTSKI, L. S.; LURIA, A. R. El instrumento y el signo en el desarrolho del niño. Madrid:

Fundación Infancia y Aprendizaje, 2007.

VYGOTSKI, L. S. Obras escogidas III. Madri: Visor, 1983.

. Obras escogidas $V$ : fundamentos de defectología. Madri: Visor, 1997.

. Manuscrito de 1929. Educação \&

Sociedade, Campinas, n. 71, 2000. Disponível em: http://www.scielo.br/pdf/es/v21n71/a02v2171.pdf. Acesso em: 26 jan. 2018.

- A construção do pensamento e da linguagem. 2 ed. São Paulo: Martins Fontes, 2009. 


\section{Sobre as autoras}

Emilene Coco dos Santos é Doutora em Educação pela Universidade Federal do Espírito Santo, professora efetiva da Secretaria Municipal de Educação de Vitória/ES, atuando como assessora pedagógica na modalidade Educação Especial. Integra o Grupo de Estudo sobre Autismo, vinculado ao Núcleo de Ensino, Pesquisa e Extensão em Educação Especial da Universidade Federal do Espírito Santo.

Ivone Martins de Oliveira é professora titular da Universidade Federal do Espírito Santo. Integra a Linha de Pesquisa Educação Especial e Processos Inclusivos, do Programa de Pós-Graduação em Educação da mesma universidade. É coordenadora do Grupo de Pesquisa "Desenvolvimento Humano e Práticas Educativas em Espaços Escolares e não Escolares". Desenvolve estudos sobre aprendizagem, desenvolvimento e práticas educativas em uma perspectiva inclusiva.

Recebido em julho de 2018.

Aprovado em outubro de 2018. 